\title{
Optimization of fixation methods for observation of bacterial cell morphology and surface ultrastructures by atomic force microscopy
}

\author{
Yuanqing Chao $\cdot$ Tong Zhang
}

Received: 10 June 2011 /Revised: 6 August 2011 /Accepted: 13 August 2011 /Published online: 1 September 2011

(C) The Author(s) 2011. This article is published with open access at Springerlink.com

\begin{abstract}
Fixation ability of five common fixation solutions, including $2.5 \%$ glutaraldehyde, $10 \%$ formalin, $4 \%$ paraformaldehyde, methanol/acetone (1:1), and ethanol/acetic acid (3:1) were evaluated by using atomic force microscopy in the present study. Three model bacteria, i.e., Escherichia coli, Pseudomonas putida, and Bacillus subtilis were applied to observe the above fixation methods for the morphology preservation of bacterial cells and surface ultrastructures. All the fixation methods could effectively preserve cell morphology. However, for preserving bacterial surface ultrastructures, the methods applying aldehyde fixations performed much better than those using alcohols, since the alcohols could detach the surface filaments (i.e., flagella and pili) significantly. Based on the quantitative and qualitative assessments, the $2.5 \%$ glutaraldehyde was proposed as a promising fixation solution both for observing morphology of both bacterial cell and surface ultrastructures, while the methonal/acetone mixture was the worst fixation solution which may obtain unreliable results.
\end{abstract}

Keywords Fixation methods · Cell morphology ·

Ultrastructure - Atomic force microscopy

\section{Introduction}

The observation of the morphology of bacterial cell and their ultrastructures is fundamental for understanding the structure

Electronic supplementary material The online version of this article (doi:10.1007/s00253-011-3551-5) contains supplementary material, which is available to authorized users.

Y. Chao $\cdot$ T. Zhang $(\bowtie)$

Environmental Biotechnology Laboratory,

The University of Hong Kong,

Pokfulam Road,

Hong Kong, SAR, China

e-mail: zhangt@hkucc.hku.hk and behavior of bacteria, since morphology is one way for bacteria to cope with their environment and gain a competitive advantage (Young 2007). To facilitate accurate observation, various fixation methods were widely applied to fix cells (Moloney et al. 2004). The main objectives of fixation were to inhibit cellular autolysis, to preserve cellular components and morphology, and to present cells with a distinct microscopical appearance (Paavilainen et al. 2010). Fixation methods can be divided into two groups: additive and denaturing fixations (StLaurent et al. 2006). Additive fixation solutions (also called cross-linking fixations) contain various aldehydes, including formaldehyde, paraformaldehyde, glutaraldehyde, etc., and can create covalent chemical bonds between proteins (Dapson 2007). This method can preserve the natural structure of proteins, i.e., secondary and tertiary structures (Meade et al. 2010). Another group is the denaturing (or precipitating) fixations. These methods can denature proteins by reducing their solubility and/or disrupting the hydrophobic interactions, and thus modify the tertiary structures of proteins as well as inactivate enzymes (St-Laurent et al. 2006). Alcohols, such as methanol and ethanol, are commonly used for denaturing fixation. However, alcohols are seldom solely applied since they can induce serious cell shrinkage. Other denaturing chemicals, like acetone and acetic acid, are usually combined with alcohols to enhance the fixation performance (Moloney et al. 2004).

To select the promising fixation methods, a number of studies have been conducted to evaluate the performance of different methods in fixing various cells or tissues (Suthipintawong et al. 1996; Hoetelmans et al. 2001; Moloney et al. 2004; Vekemans et al. 2004; Celie et al. 2005; St-Laurent et al. 2006; Meade et al. 2010). Unfortunately, the above studies mainly focused on the cells or tissues from animals or human. The effects of different fixation methods on bacterial morphology were rarely studied, and thus research gaps still remained in this issue. 
Microscopical methods were commonly used in previous studies to evaluate the performance of the fixation methods, including light microscopy (St-Laurent et al. 2006), reflection contrast microscopy (Hoetelmans et al. 2001), fluorescence microscopy (Celie et al. 2005), Raman microscopy (Meade et al. 2010), electron microscopy (Hoetelmans et al. 2001), as well as atomic force microscopy (Moloney et al. 2004). Atomic force microscopy (AFM) has been widely used in all fields of surface science since its invention in 1986, including microbiological studies (Bolshakova et al. 2004). Comparing with other traditional microscopes, one of AFM's advantages is acquiring three-dimensional morphological images at nanometer or sub-nanometer scales under either dry or wet conditions (Gaboriaud and Dufrêne 2007). This provides great application potentials for quantitative measurements of the morphology of bacterial cells and surface ultrastructures. A few previous studies evaluated the effects of different AFM scanning modes on the cell morphology of several bacteria (Camesano et al. 2000; Bolshakova et al. 2001; Pelling et al. 2005; Arce et al. 2009). Moreover, the bacterial ultrastructures, including flagella (Touhami et al. 2006), pili (Pelling et al. 2005; Touhami et al. 2006; Arce et al. 2009), and capsules (Stukalov et al. 2008), were also observed and quantified, based on the exquisite sensitivity and high spatial resolution of AFM. However, as far as we know, studies were rarely conducted to evaluate the effects of fixation methods on morphology of bacterial cells and ultrastructures by using AFM.

To fill the mentioned research gaps, the present study was conducted to determine the effects of different fixation methods on the morphology of bacterial cell and its ultrastructures by using AFM and to evaluate the fixation ability of applied methods via both qualitative and quantitative assessments.

\section{Materials and methods}

\section{Bacterial strains and culture}

Three reference bacterial strains were used in the present study. Two Gram-negative bacteria, Escherichia coli wildtype strain K-12 and Pseudomonas putida DSM 291 type strain, were purchased from the E. coli Genetic Stock Center (Department of Biology, Yale University) and Deutsche Sammlung von Mikroorganismen und Zellkulturen $\mathrm{GmbH}$ (DSMZ), respectively. Gram-positive bacterium, Bacillus subtilis ATCC 6633, was purchased from Difco Laboratories (Detroit, USA).

The bacteria were cultivated at $37^{\circ} \mathrm{C}$ and $150 \mathrm{rpm}$ in sterilized $\left(121^{\circ} \mathrm{C}\right.$ for $\left.20 \mathrm{~min}\right)$ Luria-Bertani (LB) medium. Then, the cells were harvested in the Log phase at a concentration equivalent to an optical density at $600 \mathrm{~nm}$
$\left(\mathrm{OD}_{600 \mathrm{~nm}}\right)$ value of $\sim 0.1$. These bacterial cells were then used for further experiments immediately.

\section{Substrata preparation}

Glass slide was chosen as the substratum for AFM measurement in the present study. Glass slides were firstly immersed in ethanol/HCl $(v / v 70 / 1)$ solution overnight. After that, slides were washed by sonication for $10 \mathrm{~min}$ in sterilized DI water. This procedure was repeated twice. Then, the washed slides were placed in sterilized Petri dishes and dried at room temperature for $12 \mathrm{~h}$. Finally, the prepared glass slides were stored in a desiccator before use.

Fixation methods

Before fixation, bacterial cells were washed twice in phosphate-buffered saline (PBS, $8.475 \mathrm{~g} \mathrm{NaCl}, 1.093 \mathrm{~g}$ $\mathrm{Na}_{2} \mathrm{HPO}_{4}$, and $0.276 \mathrm{~g} \mathrm{NaH} \mathrm{PO}_{4}$ in $1 \mathrm{~L}$ DI water; $\mathrm{pH}$ 7.4). Five common fixation methods (Moloney et al. 2004; Celie et al. 2005) were applied to fix the washed cells, including $2.5 \%$ glutaraldehyde in PBS for $2 \mathrm{~h}, 4 \%$ paraformaldehyde in PBS for $30 \mathrm{~min}, 10 \%$ formalin in PBS for $10 \mathrm{~min}$, methanol/acetone (1:1) for $10 \mathrm{~min}$, and ethanol/acetic acid (3:1) for $10 \mathrm{~min}$. All fixations were conducted at room temperature. After fixation, the cells were washed twice in PBS and then re-suspended in sterilized ultrapure water to avoid salts crystallization during dry process and subsequent influence on AFM measurement. Finally, $100 \mu \mathrm{L}$ of prepared bacterial solution was dripped onto the glass slide and air-dried. All the samples were stored at $4^{\circ} \mathrm{C}$ before AFM measurement. All fixation methods were conducted with two to three duplicates.

\section{AFM measurements}

AFM images were acquired by using tapping mode of JPK NanoWizard AFM (JPK Instruments, Germany). Silicon cantilever Tap300 (Budgetsensors, Bulgaria) with a resonance frequency of $300 \mathrm{kHz}$ and a spring constant of $40 \mathrm{~N} /$ $\mathrm{m}$ was applied to analyze the air-dried samples in air. The tip radius of cantilever is less than $10 \mathrm{~nm}$ and opening angle is between $40^{\circ}$ and $50^{\circ}$ according to the manufacturer. To decrease the applied force between cantilever tip and bacteria to minimize the influence to the bacterial morphology during AFM scanning, the amplitude set point was maintained at a high level relative to the free amplitude of the cantilever (Camesano et al. 2000), since the applied force to sample from cantilever is negatively correlated with the amplitude value under AFM tapping mode. Measurements were started by scanning a random area of $50 \times 50 \mu^{2}$ which could contain several to dozens of bacterial cells. These images were used to evaluate the morphology of bacterial cells. 
Then, the scan size was decreased gradually until bacterial pili or flagella could be observed clearly.

Amplitude and phase images were recorded simultaneously with height images. Height images revealed the sample topography and were applied to quantify the morphology of bacterial cells, flagella, and pili. Height images were also used to calculate the roughness of bacterial surface based on root mean square (RMS) values, i.e., the standard deviation of all the height values within the given area (Camesano et al. 2000). RMS roughness was widely used as an important parameter to describe bacterial morphology in previous studies (Auerbach et al. 2000; Camesano et al. 2000; Pelling et al. 2005; Alsteens et al. 2008; Andre et al. 2010). The measurements were conducted over two different areas $\left(0.5 \times 0.5 \mu^{2}\right)$ on the surface of one individual cell, and there were 10 to 20 measurement duplicates for each bacterium/fixation combination. Amplitude images were captured to analyze surface features since they have higher sensitivity than height images (Pelling et al. 2005). Phase images were applied to reveal the sample heterogeneity since the phase signal is sensitive to properties of the tip-sample interaction and may show overall mechanical, chemical, and topographic properties of the samples (Camesano et al. 2000). More than eight images were captured for each treatment. Ten to twenty cells, flagella, and pili were taken into morphology analysis for each treatment.

Noticeably, due to the "side-wall" artifact (Fig. S1), the image width of bacterial filaments (e.g., flagella and pili) might be overestimated comparing to their true width (Bolshakova et al. 2004; Harada et al. 2008; Kuznetsov and McPherson 2011). The error between the image and true width is a function of the width of the cantilever tip (Kuznetsov and McPherson 2011). In the present study, the error was predicted and the true width of bacterial filaments was corrected to accurately evaluate the fixation ability (please refer to the Supporting information for details). For bacterial cells, no correction was conducted since the "sidewall" artifact could be negligible at micron scale.

\section{Results}

Effect of fixation methods on cell morphology

As shown in Fig. 1, single E. coli (Fig. 1a) and P. putida (Fig. 1b) cells were evenly separated on the glass slide, while B. subtilis formed multicellular chains (Fig. 1c). The morphological data (Table 1) showed that the fixed and unfixed cells were flattened on the glass slide since the height values of bacteria were lower than the width values. Thus, to quantitatively evaluate the effect of fixation methods on bacterial morphology, the width/height ratio
$(W / H)$ was firstly used as an index to reflect the preservation of bacterial cell shape after fixation since the natural $W / H$ of an intact cell is about one for rod-shaped bacteria. The results in Table 1 showed that all the $W / H$ values of cells after the fixation treatments were significantly lower $(P<0.01)$ than those of no fixation treatments except for $P$. putida $(P=0.09)$ and B. subtilis $(P=0.87)$ treated by the methanol/acetone mixture. This revealed that the applied fixation methods could reduce the influence of dehydration during air-dry process and therefore effectively maintain cell morphology. Among these fixation solutions, the ethanol/acetic acid solution performed the best since the $W / H$ ratios of cells fixed by it was the closest to 1 , especially for $P$. putida and B. subtilis. The $2.5 \%$ glutaraldehyde, $10 \%$ formalin, and $4 \%$ paraformaldehyde solutions showed their medium preservation ability, while the methanol/acetone solution had the highest $W / H$ and therefore showed the worst performance among the five fixation methods.

Bacterial surface roughness, in terms of the RMS value, was another quantitative index to evaluate the cell surface morphology. The results in Table 1 showed that the tested bacteria had rough surfaces. For the two Gram-negative strains, i.e., E. coli and P. putida, their RMS roughness values fells into the similar ranges, i.e., 9.1-20 and 8.1$21 \mathrm{~nm}$, respectively. However, the roughness of Grampositive strain $B$. subtilis was in a higher range varying from 18 to $40 \mathrm{~nm}$.

Effect of fixation methods on cell surface ultrastructures

Several cellular ultrastructures were detected from AFM images, including flagella, pili, and extracellular polymeric substance (EPS). To eliminate the "side-wall" artifacts, the corrected widths for bacterial filaments (i.e., flagella and pili) were calculated according to the image width and tip geometry of applied cantilever (please refer to Supporting information for details). Multiple flagella could be observed for all the tested bacteria, having a width of 40-90 nm and a height of 8-12 nm (Table 2). The peritrichous E. coli and $B$. subtilis had flagella all round the cell while the flagella of $P$. putida were only found at the cell pole. The flagella of bacterial cells fixed by $2.5 \%$ glutaraldehyde and $10 \%$ formalin were preserved better than those without fixation (Fig. 2). The flagella could also be detected in the treatment using $4 \%$ paraformaldehyde. However, the amount of flagella per cell decreased significantly and many of them were detached from the cell body or had incomplete structure (white arrows in Fig. 2 A-d and C-d). For the methanol/acetone and ethanol/acetic acid groups, the flagella totally disappeared.

Pili are another filamentous structure and only detected from $E$. coli. There were several distinct differences between 


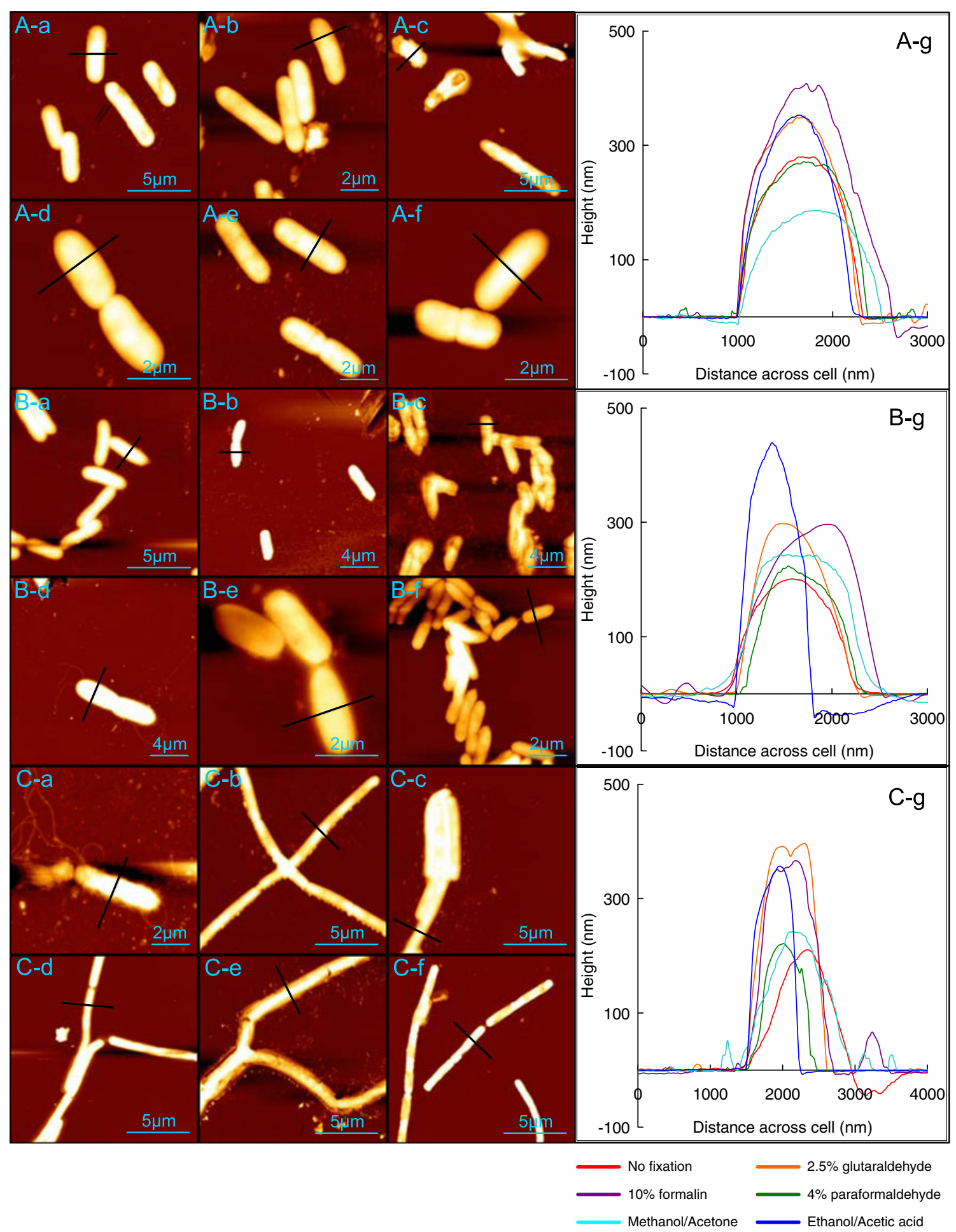

Fig. 1 AFM height images of E. coli (a), P. putida (b) and B. subtilis (c) which were air-dried only (a) and fixed by $2.5 \%$ glutaraldehyde (b), 10\% formalin (c), 4\% paraformaldehyde (d), the methanol/

pili and flagella in AFM images. First, the size of pili was significantly smaller than flagella with corrected widths of 17-33 nm and heights of 4.3-6.2 nm, respectively (Table 2). Second, the pili had linear structure while flagella were acetone (e) and ethanol/acetic acid (f) solutions. The profiles of black lines in images were shown in the figures $(A-g, B-g$, and $C-g)$ at the bottom

helical filaments. Third, the length of pili was significantly shorter than that of flagella (Figs. 2 and 3). The lengths of $E$. coli flagella and pili were $2.7 \pm 0.69$ and $0.82 \pm 0.21 \mu \mathrm{m}$, respectively $(P<0.001 ; n=10)$. The results showed that the 
Table 1 Cell morphology of E. coli, P. putida, and B. subtilis

\begin{tabular}{|c|c|c|c|c|c|c|c|}
\hline Bacteria & Fixations & Length $(\mu \mathrm{m})$ & Width $(\mu \mathrm{m})$ & Height $(\mu \mathrm{m})$ & $W / H$ ratio & RMS roughness $(\mathrm{nm})^{\mathrm{a}}$ & No. of cells \\
\hline \multirow[t]{6}{*}{ E. coli } & No fixation & $3.7 \pm 1.1$ & $1.7 \pm 0.56$ & $0.17 \pm 0.023$ & $10 \pm 3.6$ & $9.8 \pm 2.6$ & 10 \\
\hline & $2.5 \%$ Glutaraldehyde & $2.9 \pm 0.35$ & $1.2 \pm 0.28$ & $0.29 \pm 0.042$ & $4.0 \pm 0.77$ & $18 \pm 3.2$ & 10 \\
\hline & $10 \%$ Formalin & $2.9 \pm 0.39$ & $1.2 \pm 0.12$ & $0.40 \pm 0.075$ & $3.0 \pm 0.64$ & $20 \pm 4.9$ & 16 \\
\hline & 4\% Paraformaldehyde & $3.3 \pm 0.43$ & $1.2 \pm 0.090$ & $0.31 \pm 0.049$ & $4.0 \pm 0.61$ & $20 \pm 7.2$ & 18 \\
\hline & Methanol/acetone & $3.3 \pm 0.44$ & $1.4 \pm 0.047$ & $0.18 \pm 0.014$ & $7.5 \pm 0.58$ & $9.1 \pm 1.9$ & 20 \\
\hline & Ethanol/acetic acid & $2.8 \pm 0.33$ & $1.1 \pm 0.13$ & $0.37 \pm 0.050$ & $3.0 \pm 0.47$ & $19 \pm 5.0$ & 20 \\
\hline \multirow[t]{6}{*}{ P. putida } & No fixation & $3.5 \pm 0.32$ & $1.1 \pm 0.10$ & $0.16 \pm 0.020$ & $6.6 \pm 0.76$ & $8.1 \pm 3.6$ & 15 \\
\hline & 2.5\% Glutaraldehyde & $3.4 \pm 0.40$ & $1.0 \pm 0.11$ & $0.32 \pm 0.043$ & $3.2 \pm 0.50$ & $21 \pm 11$ & 16 \\
\hline & $10 \%$ Formalin & $3.3 \pm 0.33$ & $1.2 \pm 0.13$ & $0.30 \pm 0.039$ & $3.9 \pm 0.73$ & $17 \pm 7.2$ & 19 \\
\hline & $4 \%$ Paraformaldehyde & $3.4 \pm 0.40$ & $1.2 \pm 0.10$ & $0.27 \pm 0.042$ & $4.5 \pm 0.65$ & $17 \pm 4.1$ & 20 \\
\hline & Methanol/acetone & $3.3 \pm 0.31$ & $1.1 \pm 0.10$ & $0.19 \pm 0.029$ & $6.1 \pm 1.2$ & $13 \pm 5.7$ & 19 \\
\hline & Ethanol/acetic acid & $2.9 \pm 0.32$ & $0.89 \pm 0.17$ & $0.48 \pm 0.060$ & $1.8 \pm 0.26$ & $23 \pm 4.8$ & 17 \\
\hline \multirow[t]{6}{*}{ B. subtilis } & No fixation & $4.9 \pm 0.86$ & $1.1 \pm 0.20$ & $0.20 \pm 0.035$ & $5.2 \pm 0.96$ & $23 \pm 7.1$ & 17 \\
\hline & 2.5\% Glutaraldehyde & $4.8 \pm 0.85$ & $0.96 \pm 0.12$ & $0.35 \pm 0.049$ & $2.8 \pm 0.62$ & $26 \pm 7.9$ & 20 \\
\hline & $10 \%$ Formalin & $4.8 \pm 0.59$ & $0.94 \pm 0.14$ & $0.35 \pm 0.031$ & $2.7 \pm 0.47$ & $22 \pm 7.4$ & 13 \\
\hline & 4\% Paraformaldehyde & $5.0 \pm 1.3$ & $1.0 \pm 0.10$ & $0.29 \pm 0.040$ & $3.5 \pm 0.48$ & $28 \pm 13$ & 17 \\
\hline & Methanol/acetone & $4.8 \pm 0.91$ & $1.0 \pm 0.12$ & $0.20 \pm 0.042$ & $5.2 \pm 1.3$ & $18 \pm 6.6$ & 12 \\
\hline & Ethanol/acetic acid & $4.7 \pm 0.80$ & $0.86 \pm 0.065$ & $0.42 \pm 0.070$ & $2.1 \pm 0.44$ & $40 \pm 14$ & 16 \\
\hline
\end{tabular}

${ }^{\mathrm{a}} 0.5 \times 0.5 \mu \mathrm{m}^{2}$ area was used to measure the cell surface RMS roughness

pili fixed by $4 \%$ paraformaldehyde, methanol/acetone, and ethanol/acetic acid totally disappeared in AFM images (Table 3 ). For the treatment using $10 \%$ formalin, most of pili were also detached from the cell body (Fig. 3c). However, the detached pili still remained on the substrata surface, and thus their morphology could be measured. The $2.5 \%$ glutaraldehyde solution showed the best performance since the pili were intact and maintained in the natural morphology.

Table 2 Flagellar morphology of E. coli, P. putida, and B. subtilis

\begin{tabular}{|c|c|c|c|c|c|c|}
\hline Bacteria & Fixations & Image width (nm) & Corrected width (nm) & Height (nm) & $W / H$ ratio & No. of flagella \\
\hline \multirow[t]{6}{*}{ E. coli } & No fixation & $105 \pm 16$ & $88 \pm 16$ & $8.9 \pm 1.1$ & $10 \pm 1.8$ & 10 \\
\hline & $2.5 \%$ Glutaraldehyde & $55 \pm 4.2$ & $37 \pm 4.1$ & $9.9 \pm 1.9$ & $3.9 \pm 0.86$ & 12 \\
\hline & $10 \%$ Formalin & $77 \pm 9.8$ & $59 \pm 9.6$ & $10 \pm 1.4$ & $5.7 \pm 1.1$ & 15 \\
\hline & 4\% Paraformaldehyde & $81 \pm 11$ & $64 \pm 11$ & $9.6 \pm 1.5$ & $6.7 \pm 1.1$ & 11 \\
\hline & Methanol/acetone & & & N. D. ${ }^{a}$ & & \\
\hline & Ethanol/acetic acid & & & N. D. & & \\
\hline \multirow[t]{6}{*}{ P. putida } & No fixation & $86 \pm 14$ & $69 \pm 14$ & $9.5 \pm 1.3$ & $7.4 \pm 1.8$ & 15 \\
\hline & $2.5 \%$ Glutaraldehyde & $77 \pm 15$ & $59 \pm 15$ & $12 \pm 1.6$ & $5.1 \pm 1.5$ & 13 \\
\hline & $10 \%$ Formalin & $84 \pm 12$ & $67 \pm 12$ & $8.7 \pm 1.9$ & $8.0 \pm 2.0$ & 13 \\
\hline & 4\% Paraformaldehyde & $65 \pm 8.8$ & $48 \pm 8.7$ & $10 \pm 1.2$ & $4.7 \pm 1.0$ & 14 \\
\hline & Methanol/acetone & & & N. D. & & \\
\hline & Ethanol/acetic acid & & & N. D. & & \\
\hline \multirow[t]{6}{*}{ B. subtilis } & No fixation & $94 \pm 16$ & $77 \pm 16$ & $8.2 \pm 1.7$ & $9.6 \pm 2.0$ & 15 \\
\hline & $2.5 \%$ Glutaraldehyde & $80 \pm 11$ & $63 \pm 11$ & $9.8 \pm 1.0$ & $6.5 \pm 1.2$ & 20 \\
\hline & $10 \%$ Formalin & $66 \pm 11$ & $49 \pm 11$ & $9.3 \pm 1.7$ & $5.5 \pm 1.7$ & 12 \\
\hline & 4\% Paraformaldehyde & $83 \pm 11$ & $67 \pm 11$ & $8.6 \pm 1.0$ & $7.8 \pm 0.96$ & 12 \\
\hline & Methanol/acetone & & & N. D. & & \\
\hline & Ethanol/acetic acid & & & N. D. & & \\
\hline
\end{tabular}

${ }^{\mathrm{a}}$ No detection of flagella 


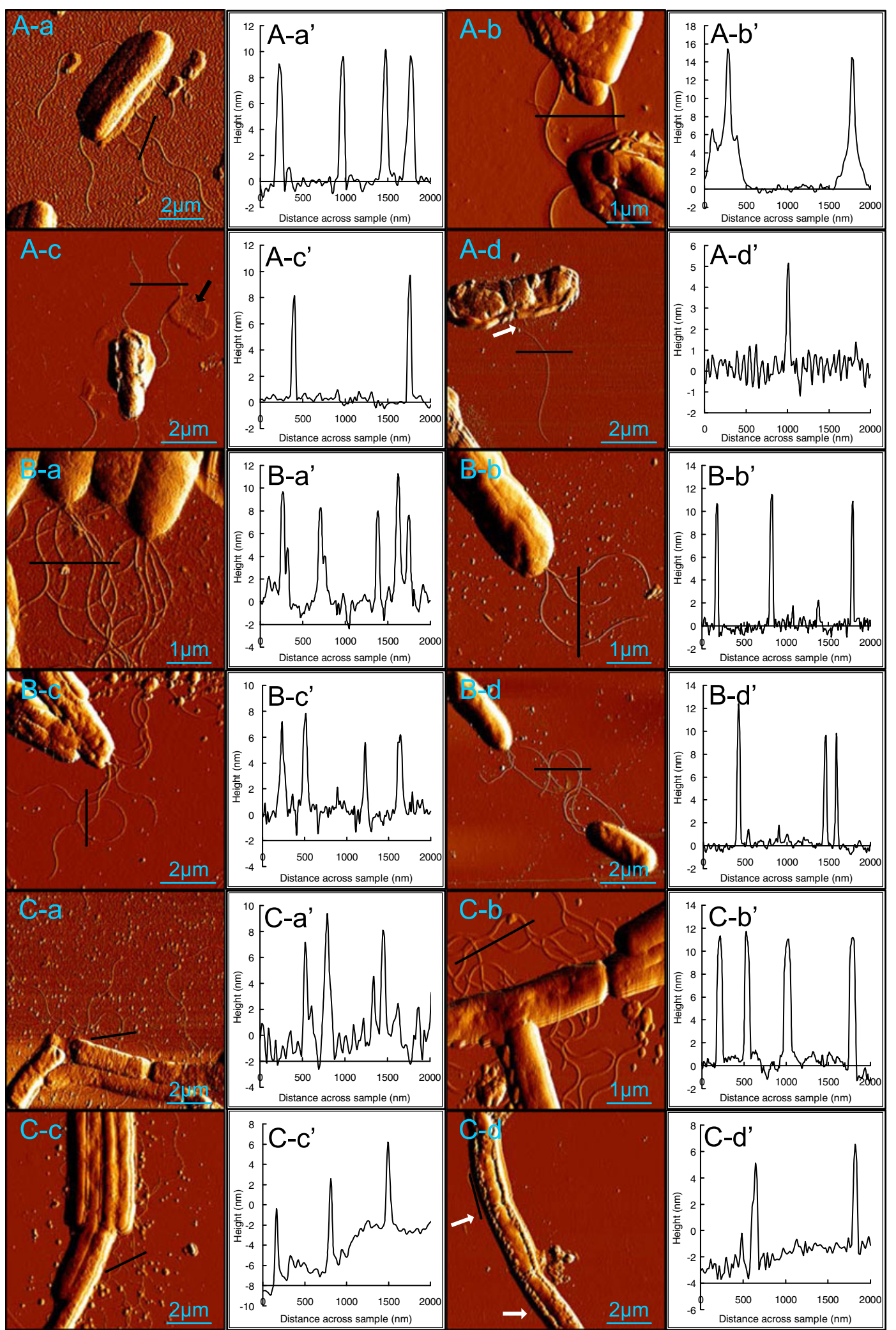

Fig. 2 AFM amplitude images of E. coli (a), P. putida (b), and B. subtilis (c) which were air-dried only (a) and fixed by $2.5 \%$ glutaraldehyde (b), 10\% formalin (c), and 4\% paraformaldehyde (d). The right images $\left(a^{\prime}, b^{\prime}, c^{\prime}\right.$, and $\left.d^{\prime}\right)$ showed the profiles of black lines obtained from corresponding height images (not shown here). The white arrows in the images of $A-d$ and $C-d$ showed a detached flagellum from $E$. coli cell body and the incomplete flagellar structure on B. subtilis cell, respectively. The black arrow in $A-c$ indicated the coating artifacts 
Fig. 3 AFM height $\left(a^{\prime}\right)$ and phase $\left(b^{\prime}\right)$ images of $E$. coli which were air-dried only (a) and fixed by $2.5 \%$ glutaraldehyde (b), 10\% formalin (c). The right images $\left(c^{\prime}\right)$ showed the profiles of black lines in height images (a). The white arrows in $c-b$ ' showed the detached pili from cell body. The black arrow in $c-b$ ' indicated the coating artifacts

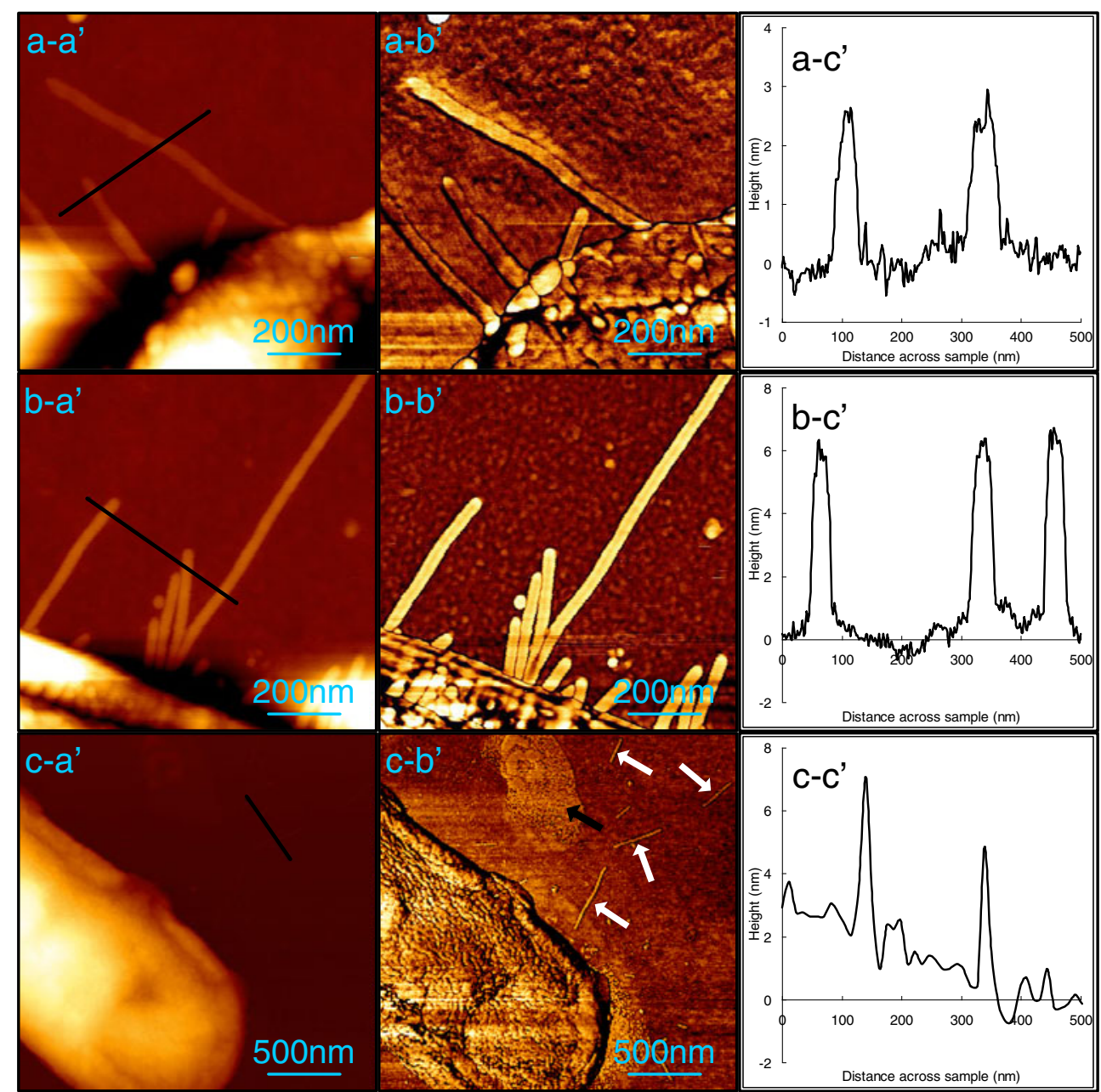

EPS could also be observed in the phase images since its physicochemical and topographic properties were different from bacterial cells (Fig. 4). The EPS of E. coli and $B$. subtilis was observed in several fixation treatments, including 10\% formalin, 4\% paraformaldehyde, and the methanol/ acetone solutions (Figs. 1, 2, and 4). This indicated other fixation methods using $2.5 \%$ glutaraldehyde, and the ethanol/acetic acid solution significantly removed the EPS.
This is a good point for observing the morphology of bacterial cells and surface ultrastructures since (1) the EPS might interfere the cell edge estimation and consequently affect the morphology observation, (2) other ultrastructures like flagella and pili might be covered by the dehydrated EPS and thus could not be observed in AFM images, and (3) EPS might contaminate the cantilever tip during scanning and finally deteriorate the image quality.

Table 3 Pili morphology of E. coli

\begin{tabular}{|c|c|c|c|c|c|}
\hline Fixations & Image width (nm) & Corrected width (nm) & Height (nm) & $W / H$ ratio & No. of pili \\
\hline No fixation & $48 \pm 9.1$ & $33 \pm 9.0$ & $4.3 \pm 0.46$ & $7.8 \pm 1.8$ & 11 \\
\hline $2.5 \%$ Glutaraldehyde & $32 \pm 2.5$ & $17 \pm 2.4$ & $6.2 \pm 0.51$ & $2.7 \pm 0.45$ & 10 \\
\hline $10 \%$ Formalin & $38 \pm 11$ & $23 \pm 11$ & $4.8 \pm 0.94$ & $5.2 \pm 3.1$ & 15 \\
\hline $4 \%$ Paraformaldehyde & & & N. D. ${ }^{a}$ & & \\
\hline Methanol/acetone & & & N. D. & & \\
\hline Ethanol/acetic acid & & & N. D. & & \\
\hline
\end{tabular}

${ }^{\mathrm{a}}$ No detection of pili 
Fig. 4 AFM phase images of $E$. coli which were air-dried only (a) and fixed by $2.5 \%$ glutaraldehyde (b), $10 \%$ formalin (c), $4 \%$ paraformaldehyde (d), methanol/acetone (e), and ethanol/acetic acid (f). The white arrow showed the surrounding EPS. The black arrows in $C$ indicated the coating artifacts

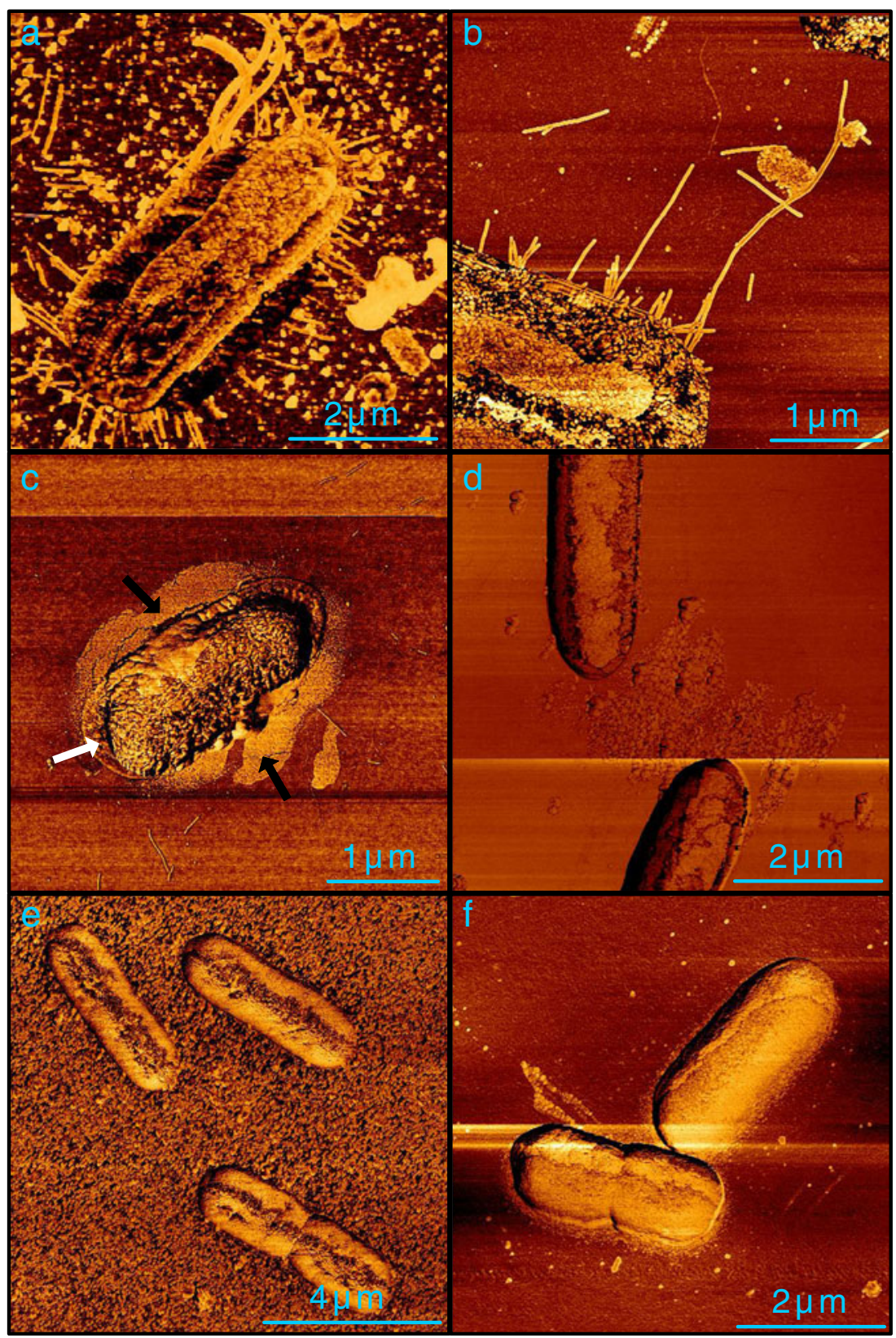

Debris and coating artifacts caused by the fixation

Two types of artifacts, i.e., debris and coating, caused by the fixation, could occur in the AFM images. The debris artifacts on the sample surface, which mainly came from disintegration of bacterial cells during washing and fixation processes, generated false morphological data and thus affected the morphology analysis significantly (Moloney et al. 2004). In AFM images, the visible debris artifacts were in smaller size than bacterial cells, had heterogeneous morphology, and commonly existed on the sample surface (Figs. 1 and 2). Based on the amount and size of debris, the ethanol/acetic acid solution seemed to be the best fixation method generating little debris. Debris with larger amount and size were found in the samples fixed by $10 \%$ formalin and the methanol/acetone solution, indicating that these two fixation methods were less preferred due to debris generation and the unreliable morphology.

Coating artifacts were a continuous layer composed of bacteria-derived materials and/or residual culture medium which deposited on the sample surface (Moloney et al. 2004). Coating artifacts might mask the true topography of bacterial surface and could also significantly interfere the bacterial morphology determination. Moreover, the surface ultrastructures, such as flagella and pili, might be embedded in this thin layer and not be able to be detected totally. Therefore, the coating effect should be taken into consideration when choosing the fixation methods. The results of the present 
study showed the coating artifacts appeared in the AFM images of several fixation methods, especially $10 \%$ formalin (black arrows in Figs. 2, 3, and 4). This revealed that the AFM images of samples fixed by $10 \%$ formalin might face the problem of coating artifacts.

\section{Discussion}

Cells and ultrastructure morphology

Several studies had been conducted to determine the cell morphology of various bacterial species using different AFM operational modes either in air or under aqueous conditions (Table 4). The observed bacteria were not natural rod- or sphere-shape, but flattened to certain extents. Several factors, including environmental variables as well as AFM operations, could significantly interfere the morphology determination (Bolshakova et al. 2004). The scanning conditions were critical for acquiring the bacterial morphology. Typically, bacterial morphology in air was flatter than those in liquid (Table 4), since the dehydration of cell and surface EPS in air might mainly affect the measurement. Another factor was AFM scanning mode, i. e., contact and tapping modes. For the contact mode, the cantilever tip was always touching with the bacterial cells under a given force during scanning. Although the selected cantilever for the contact mode was relative soft, the interaction between the cantilever tip and the cells could significantly interfere the cell morphology observation, such as bacterial distortion or detachment caused by the lateral force as well as artifacts caused by the cantilever contamination, especially for the soft cell and deformable EPS. For the tapping mode, the contact between the cantilever tip and cell surface only lasts for a small portion of oscillation cycle, i.e., about at the lowest point of an oscillation cycle. This scanning mode could significantly decrease the sample damage and lateral force (Camesano et al. 2000). In the present study, the relatively "light" tapping mode by applying larger oscillation amplitude further reduced the influence of interaction between the cantilever tip and cells on cell morphology determination.

The bacterial filamentous structures, such as flagellum and pili, were observed using AFM in a few previous studies (Pelling et al. 2005; Touhami et al. 2006; Arce et al. 2009). Unlike bacterial cells, the filamentous structures were difficult to be detected in aqueous environments via AFM since the force to detach bacterial filaments from the substrata was relatively small, and thus these structures were easily detached in a fluid medium (Touhami et al. 2006). However, it was easier to detect these filamentous structures after drying and by scanning in air since the adhesion strength increased significantly after drying (Roosjen et al. 2005). In the present study, the flagella of three tested bacteria and pili of $E$. coli

Table 4 Bacterial morphology determined by AFM under various conditions in previous studies

\begin{tabular}{|c|c|c|c|c|c|}
\hline Bacteria & $\begin{array}{l}\text { Width/diameter } \\
(\mu \mathrm{m})^{\mathrm{a}}\end{array}$ & $\begin{array}{l}\text { Height } \\
(\mu \mathrm{m})\end{array}$ & $W / H$ ratio & AFM operation & Reference \\
\hline Acinetobacter venetianus RAG-1 & $1.1 \pm 0.05$ & $0.66 \pm 0.03$ & 1.7 & Tapping mode, in phosphate buffer & Dorobantu et al. 2008 \\
\hline Escherichia coli $\mathrm{DH} 5 \alpha$ & $0.9 \pm 0.05$ & $0.4 \pm 0.02$ & 2.3 & Tapping mode, in phosphate buffer & Sahu et al. 2009 \\
\hline Escherichia coli $\mathrm{DH} 12 \mathrm{~S}$ & $1.3 \pm 0.1$ & $0.1 \pm 0.05$ & 13 & Contact mode, in air & Lomonosov et al. 2003 \\
\hline Escherichia coli $\mathrm{DH} 12 \mathrm{~S}$ & $1.5 \pm 0.2$ & $0.2 \pm 0.05$ & 7.5 & Contact mode, in distillated water & Lomonosov et al. 2003 \\
\hline Escherichia coli $\mathrm{K} 12 \mathrm{~J} 62$ & $0.83 \pm 0.06$ & $0.17 \pm 0.04$ & 4.9 & Contact mode, in air & Bolshakova et al. 2001 \\
\hline Escherichia coli $\mathrm{K} 12 \mathrm{~J} 62$ & $1.1 \pm 0.5$ & $0.26 \pm 0.05$ & 4.2 & Contact mode, in distillated water & Bolshakova et al. 2001 \\
\hline Escherichia coli JM109 & $0.8 \pm 0.1$ & $0.28 \pm 0.08$ & 2.9 & Contact mode, in air & Bolshakova et al. 2001 \\
\hline Escherichia coli JM109 & $1.1 \pm 0.2$ & $0.5 \pm 0.1$ & 2.2 & Contact mode, in distillated water & Bolshakova et al. 2001 \\
\hline Escherichia coli JM109 & $0.8 \pm 0.2$ & $0.3 \pm 0.07$ & 2.7 & Tapping mode, in air & Bolshakova et al. 2001 \\
\hline Escherichia coli JM109 & $1.0 \pm 0.4$ & $0.08 \pm 0.04$ & 13 & Tapping mode, in distillated water & Bolshakova et al. 2001 \\
\hline Escherichia coli XLIB & $0.8 \pm 0.1$ & $0.2 \pm 0.05$ & 4.0 & Contact mode, in air & Lomonosov et al. 2003 \\
\hline Escherichia coli XLIB & $1.0 \pm 0.1$ & $0.3 \pm 0.05$ & 3.3 & Contact mode, in distillated water & Lomonosov et al. 2003 \\
\hline Haemophilus influenzae PittGG & $0.76 \pm 0.15$ & $0.21 \pm 0.06$ & 3.6 & Tapping mode, in air & Arce et al. 2009 \\
\hline Haemophilus influenzae PittEE & $0.88 \pm 0.24$ & $0.26 \pm 0.07$ & 3.5 & Tapping mode, in air & Arce et al. 2009 \\
\hline Pseudomonas stutzeri $\mathrm{KC}^{\mathrm{b}}$ & 1.1 & 0.15 & 7.3 & Tapping mode, in MOPS buffer & Camesano et al. 2000 \\
\hline Rhodococcus erythropolis 20S-E1-c & $1.5 \pm 0.03$ & $0.71 \pm 0.05$ & 2.1 & Tapping mode, in phosphate buffer & Dorobantu et al. 2008 \\
\hline Staphylococcus aureus & $0.70 \pm 0.08$ & $0.35 \pm 0.05$ & 2.0 & Tapping mode, in phosphate buffer & Sahu et al. 2009 \\
\hline
\end{tabular}

${ }^{a}$ For rod-shaped bacteria, the data were widths values; for spherical bacteria, the data were diameter

${ }^{\mathrm{b}}$ The data were collected from figures of cross-section profile in reference 
were clearly observed in air, and their morphologies were determined accordingly by analyzing AFM height images.

The dimension of bacterial flagella in the present study varied between 40 and $90 \mathrm{~nm}$ in width (the "side-wall" artifact was taken into consideration) and between 8 and $12 \mathrm{~nm}$ in height (Table 2) and was compatible with the flagellar sizes of others' studies, which had a width of 17$48 \mathrm{~nm}$ and a height of 5.5-6.5 nm (Jaschke et al. 1994), as well as a width of $50-150 \mathrm{~nm}$ and a height of $\sim 4 \mathrm{~nm}$ (Schmid et al. 2008). Assuming that flagella were deformable and the cross section was ellipse, the perimeter of the ellipse was equal to that of circular cross section of natural and undeformed flagella (i.e., $L=\pi H+2(W-H)=\pi D$ ). From the corrected data of flagellar width and height, the converted diameters of the three tested bacteria could be calculated $(D=H+2(W-H) / \pi)$. The converted diameters varied from 14 to $28 \mathrm{~nm}$ for E. coli, 17 to $24 \mathrm{~nm}$ for $P$. putida, and 17 to $23 \mathrm{~nm}$ for $B$. subtilis. This was the typical dimension of bacterial flagella within the diameter of 12 to $25 \mathrm{~nm}$ (Namba and Vonderviszt 1997; Samatey et al. 2001; Maki-Yonekura et al. 2010). For E. coli pili, the dimension observed in the present study had a corrected width of 17 to $33 \mathrm{~nm}$, a height of 4 to $6 \mathrm{~nm}$, and a converted diameter of 6 to $10 \mathrm{~nm}$. This was also compatible with the typical dimension of bacterial pili, which had 4 to $7 \mathrm{~nm}$ diameter according to previous reports (Korhonen et al. 1980; Telford et al. 2006; Touhami et al. 2006; Arce et al. 2009).

\section{Effect of fixation methods}

To optimize the fixation methods for the morphology observation of bacterial cells and surface ultrastructures, five common fixation solutions were evaluated on their preservation ability in the present study. The results strongly suggested that the fixation methods could significantly affect the morphology of bacterial cell as well as the surface ultrastructures. The fixation methods containing alcohols (including the methanol/acetone and ethanol/acetic acid solutions) obtained biased morphology than those containing aldehydes (including 2.5\% glutaraldehyde, $10 \%$ formalin, and $4 \%$ paraformaldehyde), since the filamentous structures (flagella and pili) disappeared on the cell surface. This might be mainly caused by the alcohols in these fixation solutions which could dissolve the membrane lipids, form large pores in the cell, and detach the surface macromolecules on the cell surface (Vekemans et al. 2004). For the cell morphology, the ethanol/acetic acid solution could obtain better preservation than the methanol/acetone solution (Table 1 and Fig. 1). In the ethanol/acetic acid combination, acetic acid could swell cell and thus counteracted the shrinkage induced by ethanol, while the main role of acetone in the methanol/acetone solution was penetrating cell to facilitate the consequent fixation by methanol (StLaurent et al. 2006). Thus, the bacteria cell fixed by the methanol/acetone solution shrank seriously, and the bacterial morphology was poorly preserved. Other studies also revealed that no reliable morphology could be obtained after acetone/methanol fixation (Hoetelmans et al. 2001; St-Laurent et al. 2006).

The fixation methods applying aldehydes showed medium preservation ability for cell morphology judging from the $W / H$ ratios (Table 1). For bacterial filaments morphology, the aldehyde fixations performed much better than

Table 5 Assessments and comments for the applied fixation methods

\begin{tabular}{|c|c|c|c|c|c|c|c|}
\hline Fixations & $\begin{array}{l}\text { Cell morphology } \\
\text { preservation }\end{array}$ & $\begin{array}{l}\text { Flagella/pili } \\
\text { preservation }\end{array}$ & EPS removal & $\begin{array}{l}\text { Debris } \\
\text { artifacts }^{\mathrm{b}}\end{array}$ & $\begin{array}{l}\text { Coating } \\
\text { artifacts }^{b}\end{array}$ & Overall & Comments \\
\hline $2.5 \%$ Glutaraldehyde & $\circ^{a}$ & + & + & $\circ$ & ○ & + & $\begin{array}{l}\text { The best option of the applied } \\
\text { fixation methods for observing } \\
\text { morphology of both cells and } \\
\text { ultrastructures }\end{array}$ \\
\hline $10 \%$ Formalin & $\circ$ & $\circ$ & $\circ$ & - & - & ० & $\begin{array}{l}\text { The coating and debris artifacts may } \\
\text { affect morphology observation }\end{array}$ \\
\hline 4\% Paraformaldehyde & $\circ$ & - & - & $\circ$ & ○ & $\circ$ & $\begin{array}{l}\text { The existed EPS may cover surface } \\
\text { features, and some filaments like } \\
\text { pili may detach from cells }\end{array}$ \\
\hline Methanol/acetone & - & - & - & - & $\circ$ & - & $\begin{array}{l}\text { The worst fixation method which } \\
\text { may obtain biased results }\end{array}$ \\
\hline Ethanol/acetic acid & + & - & + & + & + & + & $\begin{array}{l}\text { The best option for evaluating cell } \\
\text { morphology, but poor for } \\
\text { observing bacterial filaments }\end{array}$ \\
\hline
\end{tabular}

a + means good; o means medium; - means poor

${ }^{\mathrm{b}}$ Good: little debris and coating artifacts appear; medium: debris and coating appear but not serious; poor: debris and coating appear seriously 
alcohols since aldehydes fixed cell by forming covalent chemical bonds between proteins and therefore could maintain the integrality of membrane lipids as well as the surface macromolecules (Dapson 2007). In the present study, $2.5 \%$ glutaraldehyde showed the best performance for fixation of filaments, following by $10 \%$ formalin and $4 \%$ paraformaldehyde. Paraformaldehyde, the polymerized form of formaldehyde, would be depolymerized to formaldehyde when dissolved (Kiernan 2000). Therefore, the 4\% paraformaldehyde solution contained pure formaldehyde. For the $10 \%$ formalin solution, the major component is formaldehyde but also contains $1 \%$ methanol which is added to slow down the polymerization of formaldehyde (Kiernan 2000). This might be the main reason to explain the slightly different performances between $10 \%$ formalin and $4 \%$ paraformaldehyde (Tables 1 and 2). Comparing with formaldehyde, glutaraldehyde could fix sample more tightly since it has longer molecule and two aldehyde groups which has potential to link more distant protein molecules (Kiernan 2000). This might explain the best performance of glutaraldehyde in fixing the bacterial filaments among the applied fixation methods.

The bacterial surfaces were not smooth but with lots of spherical structures (phase images in Figs. 3 and 4). These structures were always observed in the images of different bacteria fixed with aldehydes, indicating they were the bacterial morphological feature, instead of artifacts formed in drying and fixation or due to the cantilever contamination. These spherical structures were also observed in a few previous studies and considered to be the surface proteins (Camesano et al. 2000; Micic et al. 2004) and/or lipopolysaccharides (Micic et al. 2004; Handa et al. 2010; McEwen et al. 2010). Comparing with aldehyde fixations, the bacteria fixed by alcohols showed obscure spherical structures (Fig. 4). This further indicated that the alcohols could remove the surface proteins and/or lipopolysaccharides.

To comprehensively evaluate the applied fixation methods and determine which one was the most promising method, quantitative and qualitative assessments were conducted in the present study (Table 5). Quantitative assessments were based on the morphology preservation of both bacterial cell and surface filaments by comparing the $W / H$ ratios of cells fixed using different methods. Qualitative assessments were based on the EPS removal, debris, and coating artifacts by analyzing AFM images. Other possible artifacts, such as salt crystals and streaking artifacts (Moloney et al. 2004), could also affect the morphological analysis. Salt crystals might derive from washing buffer (PBS or others) after drying. To avoid crystals generation, the ultrapure water was applied to re-suspend the fixed cells before drying in air. The AFM images also showed no salt crystals generated on the sample surface. Streaking artifacts are mainly caused by the inappropriate AFM operation or tip contamination which might lead into inaccurate measurements and consequently interfere the morphology analysis, but having nothing to do with the fixation methods. In the present study, the operation parameters such as set points and scan rates were optimized in the pre-experiments and also adjusted during scanning to avoid the streaking artifacts due to inappropriate AFM operations. For bacterial samples, the tip contamination was almost inevitable since the cell or debris which adhered loosely on the cell surface easily adhered to the tip during scanning. The strategy applied in the present study was to replace the contaminated cantilever immediately with a new one when the streaking artifacts appeared in an image. Therefore, the salt crystals and streaking artifacts were not taken into consideration for the assessments of the fixation methods. Based on above assessments, several comments were also proposed in Table 5 for future applications.

Acknowledgements The authors wish to thank the Hong Kong UGC One-off Special Equipment Grant Scheme (SEG HKU10) for the financial support on this study, and Yuanqing Chao wishes to thank the University of Hong Kong for the postgraduate studentship. The technical assistance of Ms. Vicky Fung is greatly appreciated.

Open Access This article is distributed under the terms of the Creative Commons Attribution Noncommercial License which permits any noncommercial use, distribution, and reproduction in any medium, provided the original author(s) and source are credited.

\section{References}

Alsteens D, Verbelen C, Dague E, Raze D, Baulard AR, Dufrêne YF (2008) Organization of the mycobacterial cell wall: a nanoscale view. Pflugers Arch Eur J Physiol 456:117-125

Andre G, Kulakauskas S, Chapot-Chartier MP, Navet B, Deghorain M, Bernard E, Hols P, Dufrêne YF (2010) Imaging the nanoscale organization of peptidoglycan in living Lactococcus lactis cells. Nat Commun 1:27

Arce FT, Carlson R, Monds J, Veeh R, Hu FZ, Stewart PS, Lal R, Ehrlich GD, Avci R (2009) Nanoscale structural and mechanical properties of nontypeable Haemophilus influenzae biofilms. J Bacteriol 191:2512-2520

Auerbach ID, Sorensen C, Hansma HG, Holden PA (2000) Physical morphology and surface properties of unsaturated Pseudomonas putida biofilms. J Bacteriol 182:3809-3815

Bolshakova AV, Kiselyova OI, Filonov AS, Frolova OY, Lyubchenko YL, Yaminsky IV (2001) Comparative studies of bacteria with an atomic force microscopy operating in different modes. Ultramicroscopy 86:121-128

Bolshakova AV, Kiselyova OI, Yaminsky IV (2004) Microbial surfaces investigated using atomic force microscopy. Biotechnol Prog 20:1615-1622

Camesano TA, Natan MJ, Logan BE (2000) Observation of changes in bacterial cell morphology using tapping mode atomic force microscopy. Langmuir 16:4563-4572

Celie JWAM, Beelen RHJ, van den Born J (2005) Effect of fixation protocols on in situ detection of L-selectin ligands. J Immunol Methods 298:155-159

Dapson RW (2007) Macromolecular changes caused by formalin fixation and antigen retrieval. Biotech Histochem 82:133-140 
Dorobantu LS, Bhattacharjee S, Foght JM, Gray MR (2008) Atomic force microscopy measurement of heterogeneity in bacterial surface hydrophobicity. Langmuir 24:4944-4951

Gaboriaud F, Dufrêne YF (2007) Atomic force microscopy of microbial cells: application to nanomechanical properties, surface forces and molecular recognition forces. Colloids Surf B 54:10-19

Handa H, Gurczynski S, Jackson MP, Mao G (2010) Immobilization and molecular interactions between bacteriophage and lipopolysaccharide bilayers. Langmuir 26:12095-12103

Harada Y, Sone H, Hosaka S (2008) Estimation of three-dimensional atomic force microscope tip shape from atomic force microscope image for accurate measurement. Jpn J Appl Phys 47:6186-6189

Hoetelmans RWM, Prins FA, Cornelese-ten Velde I, van der Meer J, van der Velde CJH, van Dierendonck JH (2001) Effects of acetone, methanol, or paraformaldehyde on cellular structure, visualized by reflection contrast microscopy and transmission and scanning electron microscopy. Appl Immunohistochem Mol Morphol 9:346-351

Jaschke M, Butt HJ, Wolff EK (1994) Imaging flagella of Halobacteria by atomic force microscopy. Analyst 119:1943-1946

Kiernan JA (2000) Formaldehyde, formalin, paraformaldehyde and glutaraldehyde: what they are and what they do. Microsc Today 00-1:8-12

Korhonen TK, Lounatmaa K, Ranta H, Kuusi N (1980) Characterization of type 1 pili of Salmonella typhimurium LT2. J Bacteriol 144:800-805

Kuznetsov YG, McPherson A (2011) Atomic force microscopy in imaging of viruses and virus-infected cells. Microbiol Mol Biol Rev 75:268-285

Lomonosov AM, Egorov SN, Gallyamov MO, Yaminsky IV (2003) AFM of bacterial cells subjected to different factors. Phys LowDim Struct 3(4):125-130

Maki-Yonekura S, Yonekura K, Namba K (2010) Conformational change of flagellin for polymorphic supercoiling of the flagellar filament. Nat Struct Mol Biol 17:417-423

McEwen GD, Wu YZ, Zhou AH (2010) Probing nanostructures of bacterial extracellular polymeric substances versus culture time by Raman microspectroscopy and atomic force microscopy. Biopolymers 93:171-177

Meade AD, Clarke C, Draux F, Sockalingum GD, Manfait M, Lyng FM, Byrne HJ (2010) Studies of chemical fixation effects in human cell lines using Raman microspectroscopy. Anal Bioanal Chem 396:1781-1791

Micic M, Hu D, Suh YD, Newton G, Romine M, Lu HP (2004) Correlated atomic force microscopy and fluorescence lifetime imaging of live bacterial cells. Colloids Surf B 34:205-212

Moloney M, McDonnell L, O'Shea H (2004) Atomic force microscopy of BHK-21 cells: an investigation of cell fixation techniques. Ultramicroscopy 100:153-161
Namba K, Vonderviszt F (1997) Molecular architecture of bacterial flagellum. Q Rev Biophys 30:1-65

Paavilainen L, Edvinsson A, Asplund A, Hober S, Kampf C, Pontén F, Wester K (2010) The impact of tissue fixatives on morphology and antibody-based protein profiling in tissues and cells. $\mathrm{J}$ Histochem Cytochem 58:237-246

Pelling AE, Li Y, Shi W, Gimzewski JK (2005) Nanoscale visualization and characterization of Myxococcus xanthus cells with atomic force microscopy. Proc Natl Acad Sci U S A 102:6484-6489

Roosjen A, Boks NP, van der Mei HC, Busscher HJ, Norde W (2005) Influence of shear on microbial adhesion to PEO-brushes and glass by convective-diffusion and sedimentation in a parallel plate flow chamber. Colloids Surf B 46:1-6

Sahu K, Bansal H, Mukherjee C, Sharma M, Gupta PK (2009) Atomic force microscopic study on morphological alterations induced by photodynamic action of toluidine blue $\mathrm{O}$ in Staphylococcus aureus and Escherichia coli. J Photochem Photobiol B 96:9-16

Samatey FA, Imada K, Nagashima S, Vonderviszt F, Kumasaka T, Yamamoto M, Namba K (2001) Structure of the bacterial flagellar protofilament and implications for a switch for supercoiling. Nature 410:331-337

Schmid T, Burkhard J, Yeo BS, Zhang W, Zenobi R (2008) Towards chemical analysis of nanostructures in biofilms I: imaging of biological nanostructures. Anal Bioanal Chem 391:1899-1905

St-Laurent J, Boulay ME, Prince P, Bissonnette E, Boulet LP (2006) Comparison of cell fixation methods of induced sputum specimens: an immunocytochemical analysis. J Immunol Methods 308:36-42

Stukalov O, Korenevsky A, Beveridge TJ, Dutcher JR (2008) Use of atomic force microscopy and transmission electron microscopy for correlative studies of bacterial capsules. Appl Environ Microbiol 74:5457-5465

Suthipintawong C, Leong ASY, Vinyuvat S (1996) Immunostaining of cell preparations: a comparative evaluation of common fixatives and protocols. Diagn Cytopathol 15:167-174

Telford JL, Barocchi MA, Margarit I, Rappuoli R, Grandi G (2006) Pili in Gram-positive pathogens. Nat Rev Microbiol 4:509-519

Touhami A, Jericho MH, Boyd JM, Beveridge TJ (2006) Nanoscale characterization and determination of adhesion forces of Pseudomonas aeruginosa pili by using atomic force microscopy. $\mathrm{J}$ Bacteriol 188:370-377

Vekemans K, Rosseel L, Wisse E, Braet F (2004) Immuno-localization of Fas and FasL in rat hepatic endothelial cells: influence of different fixation protocols. Micron 35:303-306

Young KD (2007) Bacterial morphology: why have different shapes? Curr Opin Microbiol 10:596-600 